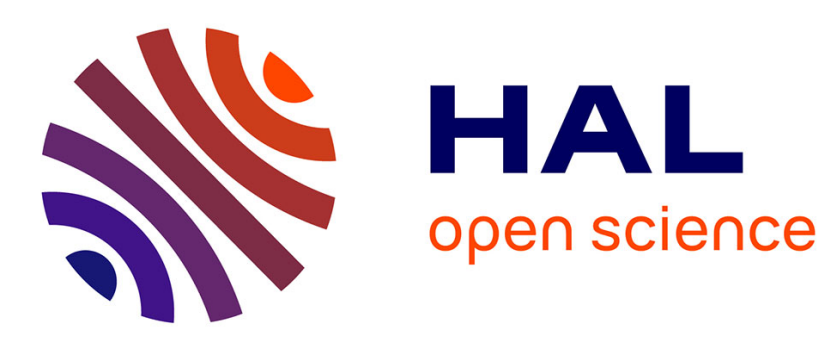

\title{
Aerobic Copper-Mediated Domino Three-Component Approach to 2-Aminobenzothiazole Derivatives
}

Thomas Castanheiro, Jean Suffert, Mihaela Gulea, Morgan Donnard

\section{To cite this version:}

Thomas Castanheiro, Jean Suffert, Mihaela Gulea, Morgan Donnard. Aerobic Copper-Mediated Domino Three-Component Approach to 2-Aminobenzothiazole Derivatives. Organic Letters, 2016, 18 (11), pp.2588-2591. 10.1021/acs.orglett.6b00967 . hal-01874301

\section{HAL Id: hal-01874301 https://hal.science/hal-01874301}

Submitted on 14 Sep 2018

HAL is a multi-disciplinary open access archive for the deposit and dissemination of scientific research documents, whether they are published or not. The documents may come from teaching and research institutions in France or abroad, or from public or private research centers.
L'archive ouverte pluridisciplinaire HAL, est destinée au dépôt et à la diffusion de documents scientifiques de niveau recherche, publiés ou non, émanant des établissements d'enseignement et de recherche français ou étrangers, des laboratoires publics ou privés. 


\title{
Aerobic Copper-Mediated Domino Three-Component Approach to 2-Aminobenzothiazole Derivatives
}

\author{
Thomas Castanheiro, Jean Suffert, Mihaela Gulea,* and Morgan Donnard* \\ Laboratoire d'Innovation Thérapeutique (UMR 7200), Faculté de Pharmacie, Université de Strasbourg, CNRS, 74 Route du Rhin, \\ 67401 Illkirch, France
}

\section{Supporting Information}

ABSTRACT: An unprecedented three-component reaction involving a 2,2'diaminodiaryl disulfide, copper cyanide, and an electrophile is described. This transformation is based on an oxidative copper-mediated S-cyanation as a key step and involves a cyanation/cyclization/acylation domino sequence enabling a rapid and efficient synthesis of diversely substituted 2 -aminobenzothiazole derivatives. Notably, this reaction proceeds via an original mechanism involving an intermolecular migration of the acyl group.

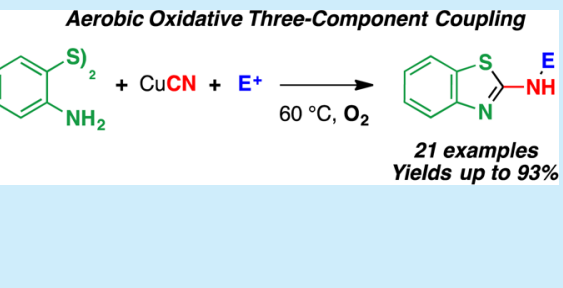

A mong the various copper-mediated reactions, ${ }^{1}$ aerobic oxidative cross-couplings represent a powerful method for the construction of carbon-carbon and carbon-heteroatom bonds. ${ }^{2}$ These transformations have been widely investigated during the last 15 years and led to elegant syntheses of simple to complex molecules. However, if only very few examples of their incorporation into domino multicomponent reactions (MCRs) $)^{3,4}$ are reported, none of them includes a cyclization step leading to polycyclic compounds. This strategy would be particularly attractive, as aerobic copper-mediated reactions generally take place under mild reaction conditions, do not require specific precursors such as aromatic halides, and are tolerant of a large number of functional groups. Moreover, the involvement of aerobic copper-mediated cross-coupling as a key step in MCRs will complement the copper-catalyzed domino reactions approach, ${ }^{5}$ providing efficient atom- and stepeconomic accesses to a large diversity of cyclic and heterocyclic structures.

Due to their pharmacological importance, ${ }^{6} 2$-aminobenzothiazoles represent a major class of heterocycles, and their synthesis ${ }^{7}$ still attracts a major attention from the organic chemistry community. For instance, this motif can be found in drugs used to treat diabetes, epilepsy, Alzheimer's disease, or viral infections. The most emblematic representative of this class of compound is undoubtedly riluzole, which is a classical treatment of amyotrophic lateral sclerosis (ALS), a lethal neurodegenerative disease.

Our group has recently reported the aerobic coppermediated cyanation of thiols/disulfides to obtain aromatic thiocyanates. ${ }^{8}$ This reaction is performed in the presence of $\mathrm{CuCN}$ in acetonitrile and requires the use of TMEDA as ligand. ${ }^{9}$ To extend its synthetic applicability, we have envisioned that this method could be integrated in a domino three-component (3CR) sequence involving aromatic thiols or disulfides bearing an amino group at the ortho position. If it has already been established that 2-aminophenyl thiocyanate can cyclize to produce 2 -aminobenzothiazole, ${ }^{10}$ this aerobic method allows selective cyanation of the sulfur atom over the nitrogen atom without specific preliminary protection. In our specific case, the nitrogen will then induce a cyclization on the newly formed thiocyanate that would drive to an amide that could subsequently be quenched by an electrophile, reaching diversely substituted 2-aminobenzothiazole derivatives (Scheme 1). The

Scheme 1. Proposed Domino 3CR To Access 2Aminobenzothiazole Derivatives

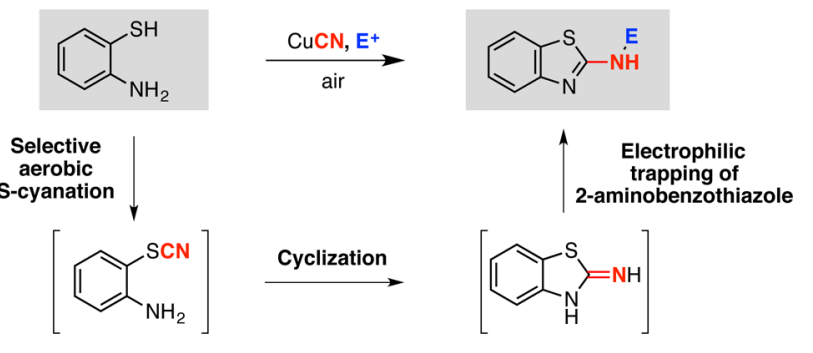

overall transformation is challenging as competitive reactions (for example, the mono- or diacylation of the aniline when the electrophile is an acyl chloride ${ }^{11}$ or the direct reaction of $\mathrm{CuCN}$ with the electrophile ${ }^{12}$ ) would prevent access to the desired product.

To validate our approach to 2 -aminobenzothiazoles via $S$ cyanation/cyclization, we first performed the reaction between 2,2'-diaminodiphenyl disulfide $\mathbf{1}$ and copper cyanide under similar reaction conditions to those we reported previously without the presence of an electrophile (Scheme 2). The reaction drove to the expected product $4 \mathbf{a}$ in a decent yield of $57 \%$. Notably, it appeared that the reaction needed around $1 \mathrm{~h}$ to reach completion at $60{ }^{\circ} \mathrm{C}$, and a longer reaction time drove the degradation of the newly formed 2-aminobenzothiazole and thus to an erosion of the yield proportional to the additional time. It appeared also that the reaction could not be performed

Received: April 4, 2016

Published: May 18, 2016 
Scheme 2. Copper-Mediated Domino Three-Component Reaction Using Acid Chlorides as Electrophiles
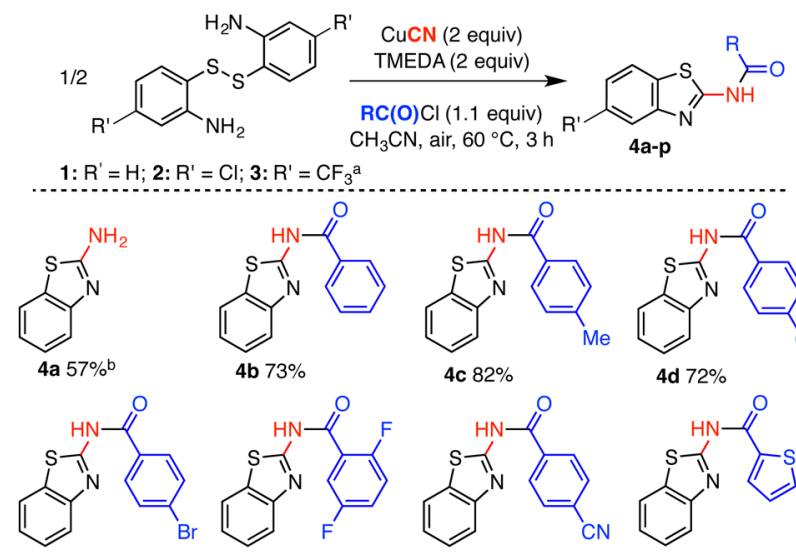

4f $80 \%$
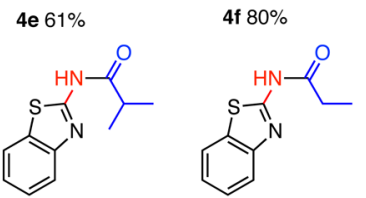

4j $76 \%$
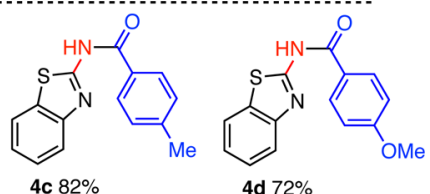

$4 \mathrm{c} 82 \%$
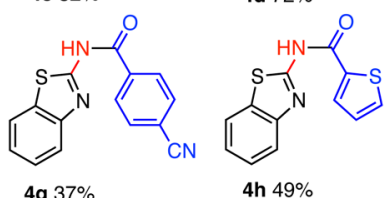

4i $77 \%$
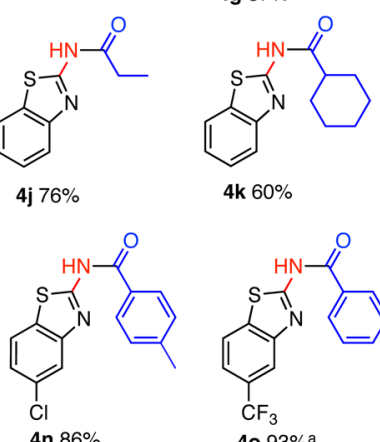

$4 k 60 \%$

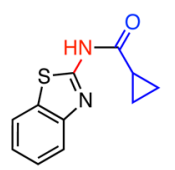

4I $61 \%$

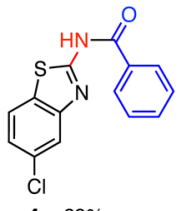

4n $86 \%$

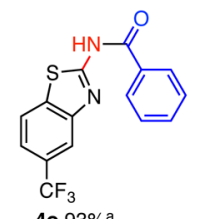

${ }^{a}$ The thiol was used as the precursor instead of the disulfide. ${ }^{b}$ Reaction performed without $\mathrm{RC}(\mathrm{O}) \mathrm{Cl}$ and stopped after $1 \mathrm{~h}$.

at room temperature as only the cyanation step took place to reach the 2-aminophenyl thiocyanate as the only product. In a second attempt, the three-component reaction was investigated by adding an acid chloride as reagent. Pleasingly, by reacting disulfide 1 with $\mathrm{CuCN}$ in the presence of benzoyl chloride, we obtained the desired product $\mathbf{4 b}$ in $73 \%$ yield (Scheme 2 ). In that case, $3 \mathrm{~h}$ was required to have a complete conversion at 60 ${ }^{\circ} \mathrm{C}$. In contrast to the reaction without an acid chloride (vide supra), it appeared during our investigation that this transformation can be performed at room temperature, but $7 \mathrm{~h}$ is then required to reach complete conversion of the starting material into $\mathbf{4 b}$ in a similar yield.

Diversely substituted benzoyl chlorides such as $p-\mathrm{Me}, p$ $\mathrm{OMe}, p-\mathrm{Br}$, and 2,5-difluoro derivatives were then investigated and furnished, respectively, products $4 \mathrm{c}, \mathbf{4 d}, \mathbf{4 e}$, and $\mathbf{4 f}$ in good yields $(61-80 \%)$. We succeeded in the isolation of a single crystal of $\mathbf{4 f}$ and obtained its structure by X-ray diffraction (Figure 1).

When the reaction was preformed using $p$-cyanobenzoyl chloride as the electrophile, an electron-poor acyl chloride, the

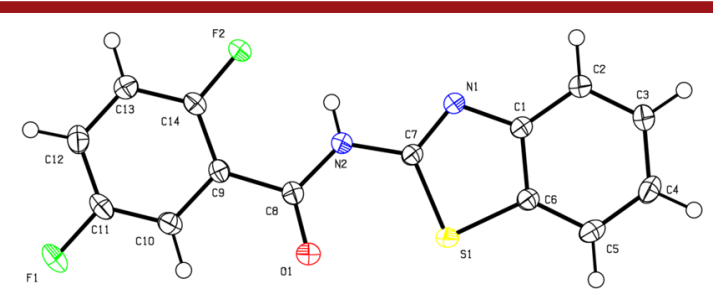

Figure 1. ORTEP view of the $X$-ray structure of $4 \mathrm{f}\left(\mathrm{R}^{1}=4.4 \%\right)$. desired product $\mathbf{4} \mathbf{g}$ was obtained in a low $37 \%$ yield. The use of a heterocyclic acid chloride such as thiophene-2-carbonyl chloride allowed us to obtain the corresponding aminobenzothiazole $4 \mathrm{~h}$ in an average $49 \%$ yield. Then the reaction was extended to aliphatic acyl chlorides such as isobutyryl chloride and propionyl chloride and led to products $4 \mathbf{i}$ and $4 \mathbf{j}$ in good $(77 \%$ and $76 \%)$ yields. Yields of the three-component reaction appeared to be slightly decreased when cyclic acid chlorides such as cyclohexanecarbonyl chloride and cyclopropanecarbonyl chloride were used and led to the corresponding 2-aminobenzothiazoles $4 k$ and 41 in $60 \%$ and $61 \%$ yields, respectively. The reaction was then extended to other substrates bearing different substituents on the aromatic ring. For instance, when 2-amino-4-chlorophenyl disulfide 2 was used as the starting material, the desired products $4 \mathrm{~m}$ and $4 n$ were obtained in good yields of $69 \%$ and $86 \%$, respectively. The reaction appeared to be even more efficient when performed with a starting material encompassing a poorer aromatic ring. Thus, starting from 2-amino-4-(trifluoromethyl)thiophenol $3^{13}$ and using benzoyl chloride as electrophile, the corresponding product 4o was obtained in an excellent $93 \%$ yield. Two particular cases (Scheme 3 ) have been identified

Scheme 3. Three-Component Reactions Leading to Valuable Side Products 5 and 6

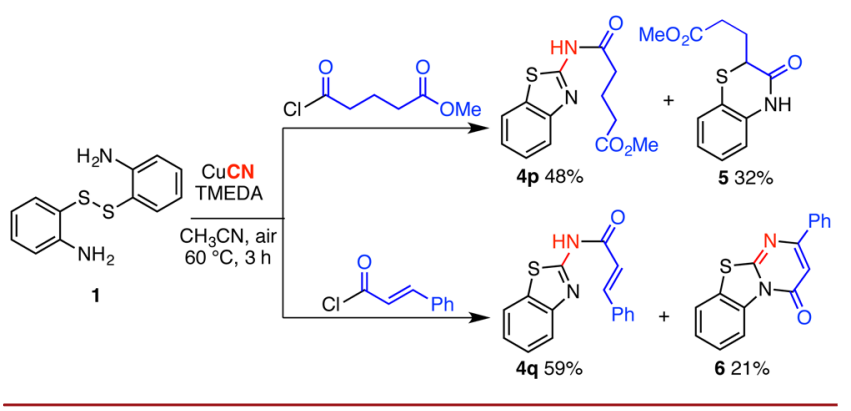

during the scope and limitation study. First, when substrate $\mathbf{1}$ was cyanated in the presence of methyl 5-chloro-5-oxopentanoate as the electrophile, the expected product $4 \mathbf{p}$ was obtained together with the benzothiazine derivative 5 (48\% and 32\%, respectively). As reported previously by Bolm et al., instead of going through an $S$-cyanation ( $\mathrm{CN}$ is not incorporated in the final structure), this side product $\mathbf{5}$ is the result of the oxidative copper-mediated cyclization of the sulfur nucleophile at the $\alpha$ position of the amide carbonyl group. ${ }^{14}$ The second particular result was obtained with cinnamoyl chloride as the electrophile. In this case, the tricyclic compound $6^{15}$ was obtained along with the expected product 4q. The new side product 6 comes from the 1,4-addition of the exocyclic nitrogen of the newly formed 2-aminobenzothiazole on the cinnamoyl double bond and subsequent oxidation under the reaction conditions.

To uncover further the scope of the three-component reaction, other types of electrophiles were investigated (Table 2 ). First, Boc anhydride was used to obtain 2-aminobenzothiazoles bearing a carbamate function on the exocyclic nitrogen. The reaction appeared to work moderately well and furnished under classical conditions the desired product 7 in $49 \%$ yield. However, the addition of $20 \%$ of DMAP as activating agent of the (Boc) ${ }_{2} \mathrm{O}$ allowed a significant increase in the yield to $71 \%$ (entry 1 ). The same reaction conditions were then applied to 6,6'-disulfanediylbis(3-chloroaniline) 2 and drove to the corresponding product 8 in a similar $65 \%$ yield 
Table 2. Domino Three-Component Reaction Using Other Electrophiles

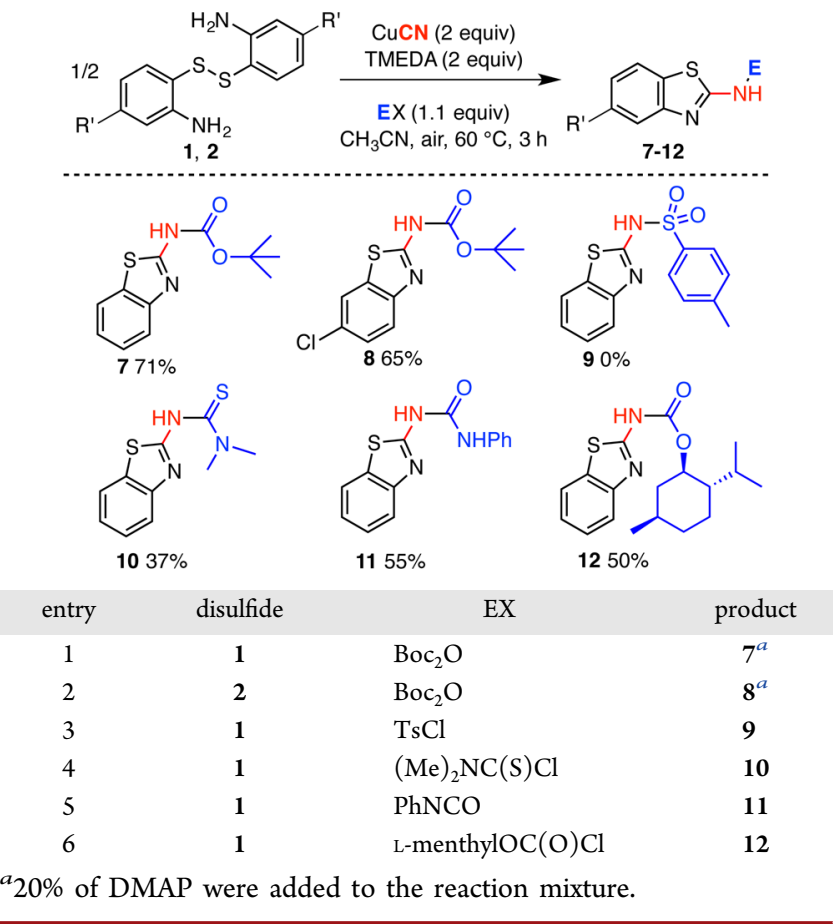

(entry 2). Attempts using tosyl chloride as electrophile remained, with or without DMAP, unsuccessful and systematically led to the degradation of the starting material without formation of the desired compound 9 (entry 3 ). The use of dimethylcarbamothioic chloride under normal conditions allowed us to obtain the corresponding aminobenzothiazole bearing a thiourea $\mathbf{1 0}$ in a modest $37 \%$ yield (entry 4 ). These species are known to be very good ligands of copper, ${ }^{16}$ suggesting that a part of the newly formed product stayed coordinated to copper complexes present in the reaction mixture. Unfortunately, different attempts to release compound 10 to increase the yield of the reaction were unsuccessful. When the reaction was performed using phenyl isocyanate as electrophile, the desired product $\mathbf{1 1}$ bearing a urea was obtained in 55\% yield (entry 5). Finally, the use of L-menthyl chloroformate as a chiral electrophile allowed us to obtain the 2-aminobenzothiazole 12 bearing a menthyl carbamate in a moderate $50 \%$ yield that can mainly be explained by the sensitivity of the product that led to a degradation of it during the purification process (entry 6).

For a better understanding of the overall process and to propose a reasonable mechanism, we performed some additional experiments. In light of the side products 5 and 6 obtained during our investigations, we presumed that the first step of the reaction could be the acylation of the aniline moiety of the starting material. Therefore, we first set out to determine if the $N, N^{\prime}$-diacylated 2,2'-diaminodiphenyl disulfide $13 \mathrm{can}$ act as the precursor of product $\mathbf{4 b}$ (Scheme 4 ).

Indeed, under our cyanation conditions, substrate $\mathbf{1 3}$ led to the same product $\mathbf{4 b}$ as that obtained from $\mathbf{1}$ in the threecomponent process (see Scheme 2) and in a similar $80 \%$ yield. Furthermore, in addition to the 2 -aminobenzothiazole $4 \mathbf{b}$, the corresponding $\mathrm{N}$-benzoyl-2-thiocyanatoaniline was isolated ( $31 \%$ yield) when the reaction was performed at room temperature.
Scheme 4. Synthesis of $4 \mathrm{~b}$ Starting from $N, N^{\prime}$-Diacylated 2,2'-Diaminodiphenyl Disulfide 13

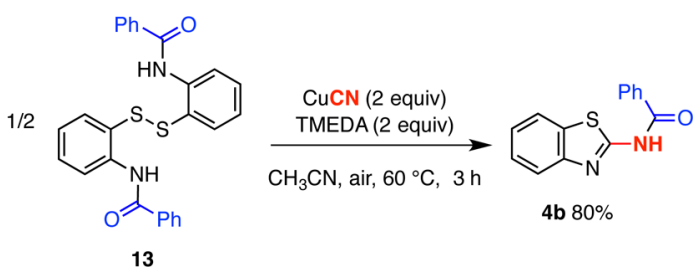

We then examined the intramolecular or intermolecular mode of the final $\mathrm{N}$-acylation when the starting material is the $N, N^{\prime}$-diacylated 2,2'-diaminodiaryl disulfide. For this purpose, we undertook a crossover experiment by placing under the cyanation conditions an equimolecular mixture of $N, N^{\prime}$ diacylated 2,2'-diaminodiaryl disulfides 13 and 14 (Scheme 5). At the end of the reaction, the analysis (by ${ }^{1} \mathrm{H}$ NMR and

Scheme 5. Crossover Experiment Starting from Disulfides 13 and 14 and $\mathrm{CuCN}$

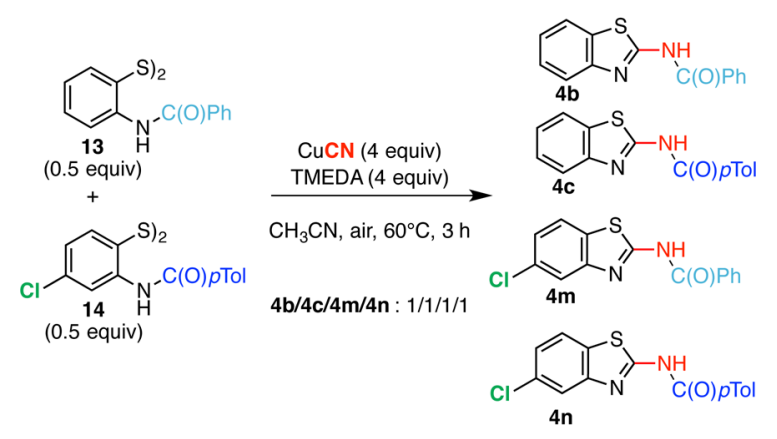

LC/MS) of the resulting mixture clearly showed crossover products $4 \mathrm{~b}, \mathbf{4 c}, \mathbf{4 m}$, and $\mathbf{4 n}$ in an almost equimolar ratio (see the Supporting Information). This result confirmed that the exocyclic nitrogen acylation takes place via an intermolecular process.

Finally, a last experiment reacting substrate $1, \mathrm{CuCN}$, and benzoyl chloride was monitored over time by TLC. After 10 min, the starting material $\mathbf{1}$ was partially transformed into the $\mathrm{N}$-acylated disulfide 13. After an additional $20 \mathrm{~min}$, product $4 \mathrm{~b}$ appeared, but remaining 1 and 13 were still detected. It appeared that the $\mathrm{N}$-acylated product seemed to undergo the $S$ cyanation faster than the nonacylated product. Then the cyclization involving the attack of a less nucleophilic amide group on the thiocyanate could take place, presumably helped by the fact that it is an intramolecular process.

In the light of those results, we can reasonably assume that the mechanism of the three-component reaction involves the following steps (Scheme 6): (I) N,N'-diacylation of the starting 2,2'-diaminodiaryl disulfide; (II) oxidative copper-mediated $S$ cyanation by $\mathrm{CuCN}$; (III) cyclization via nitrogen nucleophilic attack of the thiocyanate carbon; (IV) intermolecular acyl transfer to the exocyclic nitrogen.

In conclusion, we have developed a synthetic strategy involving for the first time an aerobic copper-mediated coupling reaction and a cyclization step in a domino multicomponent process starting from three simple precursors $\left(2,2^{\prime}\right.$-diaminodiaryl disulfide, copper cyanide, and an electrophile) under mild reaction conditions. Notably, the specific reaction mechanism that has emerged from the different experiments that were conducted during this study can undoubtedly explain how the 
Scheme 6. Proposed Mechanism Based on Experimental Observations

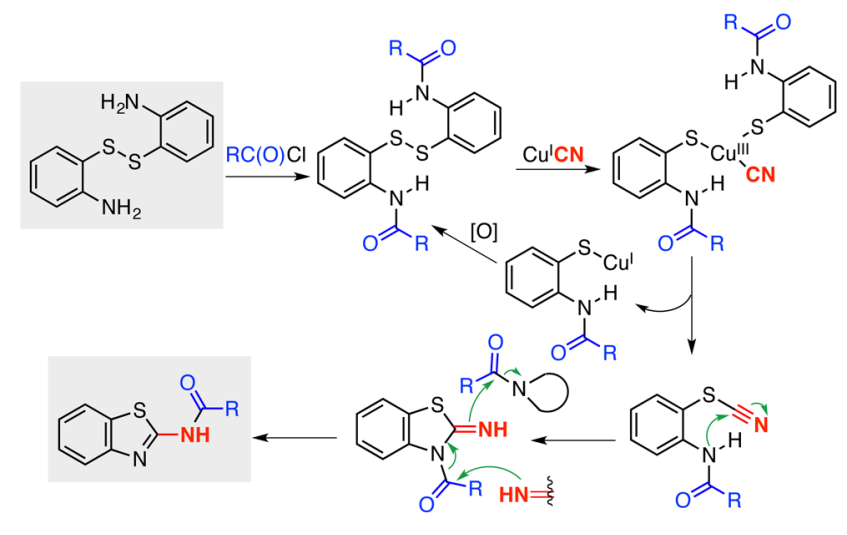

overall process passed over the diverse challenges that were exposed previously. This method represents a new, efficient access to various 2 -aminobenzothiazole derivatives.

\section{ASSOCIATED CONTENT}

\section{S Supporting Information}

The Supporting Information is available free of charge on the ACS Publications website at DOI: 10.1021/acs.orglett.6b00967.

\section{$\mathrm{X}$-ray data for $\mathbf{4 f}$ (CIF)}

Full experimental and characterization details for all compounds; X-ray crystallographic data for molecule $\mathbf{4 f}$; data to support the crossover experiment(PDF)

\section{AUTHOR INFORMATION}

\section{Corresponding Authors}

*E-mail: gulea@unistra.fr.

*E-mail: donnard@unistra.fr.

Notes

The authors declare no competing financial interest.

\section{ACKNOWLEDGMENTS}

This project was supported by the University of Strasbourg (IDEX grant for T.C.) and the Centre National de la Recherche Scientifique (CNRS). We thank Barbara Schaeffer-Lamure (mass analyses) and Dr. Lydia Karmazin (X-ray analyses) from the analytical department of the University of Strasbourg. We are also grateful to Dr. Nicolas Girard from the Faculty of Pharmacy of the University of Strasbourg for fruitful discussions.

\section{REFERENCES}

(1) For a complete review on copper-catalyzed cross-coupling reactions, see: Copper-Mediated Cross-Coupling Reactions; Evano, G., Blanchard, N., Eds.; John Wiley \& Sons: Hoboken, 2014.

(2) For a review of aerobic copper-catalyzed reactions, see: Allen, S. E.; Walvoord, R. R.; Padilla-Salinas, R.; Kozlowski, M. C. Chem. Rev. 2013, 113, 6234.

(3) (a) Li, J.; Neuville, L. Org. Lett. 2013, 15, 6124. (b) Zhai, L.; Li, Y.; Yin, J.; Jin, K.; Zhang, R.; Fu, X.; Duan, C. Tetrahedron 2013, 69, 10262. (c) Kim, J.; Stahl, S. J. Org. Chem. 2015, 80, 2448.

(4) For selected reviews on multicomponent reactions, see: (a) Multicomponent Reactions; Zhu, J., Bienayme, H., Eds; Wiley-VCH: Weinheim, 2005. (b) Hulme, C.; Gore, V. Curr. Med. Chem. 2003, 10, 51. (c) Biggs-Houck, J. E.; Younai, A.; Shaw, J. T. Curr. Opin. Chem.
Biol. 2010, 14, 371. (d) Ruijter, E.; Scheffelaar, R.; Orru, R. V. A. Angew. Chem., Int. Ed. 2011, 50, 6234. (e) Choudhury, L. H.; Parvin, T. Tetrahedron 2011, 67, 8213. (f) de Graaff, C.; Ruijter, E.; Orru, R. V. A. Chem. Soc. Rev. 2012, 41, 3969. (g) Eckert, H. Molecules 2012, 17, 1074. (h) Dömling, A.; Wang, W.; Wang, K. Chem. Rev. 2012, 112, 3083. (i) Rotstein, B. H.; Zaretsky, S.; Rai, V.; Yudin, A. K. Chem. Rev. 2014, 114, 8323.

(5) For a review on domino copper-catalyzed reactions, see: Liao, Q.; Yang, X.; Xi, C. J. Org. Chem. 2014, 79, 8507.

(6) For selected recent examples, see: (a) Namani, V.; Goud, B. B. K.; Kumari, Y. B.; Kumbham, R.; Balakrishna, K.; Bhima, B. Asian J. Chem. 2015, 27, 4575. (b) Nooka Raju, D.; Subhadra Devi, D. V. R; Grace Aghastina, D.; Govinda Rao, K.; Sathish Kumar, K. World J. Pharm. Pharm. Sci. 2015, 4, 1815. (c) Cho, H. Y.; Ul Mushtaq, A.; Lee, J. Y.; Kim, D. G.; Seok, M. S.; Jang, M.; Han, B. W.; Kim, S.; Jeon, Y. H. FEBS Lett. 2014, 588, 2851. (d) Chikhale, R.; Menghani, S.; Babu, R.; Bansode, R.; Bhargavi, G.; Karodia, N.; Rajasekharan, M. V.; Paradkar, A.; Khedekar, P. Eur. J. Med. Chem. 2015, 96, 30.

(7) For selected recent examples, see: (a) Zhao, N.; Liu, L.; Wang, F.; Li, J.; Zhang, W. Adv. Synth. Catal. 2014, 356, 2575. (b) Koppireddi, S.; Komsani, J. R.; Avula, S.; Pombala, S.; Vasamsetti, S.; Kotamraju, S.; Yadla, R. Eur. J. Med. Chem. 2013, 66, 305. (c) Ma, D.; Lu, X.; Shi, L.; Zhang, H.; Jiang, Y.; Liu, X. Angew. Chem., Int. Ed. 2011, 50, 1118. (d) Morofuji, T.; Shimizu, A.; Yoshida, J. Chem. - Eur. J. 2015, 21, 3211. (e) Toulot, S.; Heinrich, T.; Leroux, F. R. Adv. Synth. Catal. 2013, 355, 3263.

(8) (a) Castanheiro, T.; Gulea, M.; Donnard, M.; Suffert, J. Eur. J. Org. Chem. 2014, 2014, 7814. (b) Castanheiro, T.; Suffert, J.; Donnard, M.; Gulea, M. Chem. Soc. Rev. 2016, 45, 494.

(9) In the presence of copper under aerobic conditions, it has been reported that TMEDA can act as methylene or formyl source. In our case, we have never observed side products resulting from the reaction of the starting aminothiol with TMEDA. See: Zhang, L.; Peng, C.; Zhao, D.; Wang, Y.; Fu, H.-J.; Shen, Q.; Li, J.-X. Chem. Commun. 2012, 48, 5928.

(10) Erian, A. W.; Sherif, S. M. Tetrahedron 1999, 55, 7957.

(11) (a) Wang, L.; Wang, Y.; Chen, M.; Ding, M. W. Adv. Synth. Catal. 2014, 356, 1098. (b) Masu, H.; Sakai, M.; Kishikawa, K.; Yamamoto, M.; Yamaguchi, K.; Kohmoto, S. J. Org. Chem. 2005, 70, 1423.

(12) For a relevant example, see the reaction of $\mathrm{CuCN}$ with an acid chloride to form an acyl cyanide: Santelli, M.; El Abed, D.; Jellal, A. J. Org. Chem. 1986, 51, 1199.

(13) In the previous study (ref $8 a$ ), it was shown that under the reactions conditions the thiol is instantaneously transformed into disulfide.

(14) Zou, L. H.; Priebbenow, D. L.; Wang, L.; Mottweiler, J.; Bolm, C. Adv. Synth. Catal. 2013, 355, 2558.

(15) Notably, compound 6 is the first example for the synthesis of this regioisomer coming from the formal condensation of acetylenic acids and 2-aminobenzothiazoles. For the synthesis of the other regioisomer, see: Wahe, H.; Mbafor, J. T.; Nkengfack, A. E.; Fomum, Z. T.; Cherkasov, R. A.; Sterner, O.; Doepp, D. ARKIVOC 2003, No. xv, 107.

(16) Gallagher, W. P.; Vo, A. Org. Process Res. Dev. 2015, 19, 1369. 